\title{
Articles
}

Utilitarianism and Vegetarianism, Again

Peter Singer, in his essay "Utilitarianism and Vegetarianism" (Philosoohy and Public Affaiss, vol. 9, no. 4, PP. 325-37), I has gone some distance toward clarifying his view of the utilitarian case for the obligarion to be vegetarian. The fact that this clearer statement of his position was prompted, at least in part, by an essay of mine ("Utilitarianism, Vegetarianism, and Animal Rights," Philosophy and Public Affairs, vol. 9, no. 4, 305-324) provides the with some assurance that my own essay was not entirely idle, and though I am cempted to leave matcers stand at that, there are a few points in Singer's essay that constrain me to offer this brief reply. My remarks fall into three categories: (1) Misunderstandings; (2) The coherence of utilitarianism; and (3) singer's attempt to base vegetarianism on utility.

\section{(1) Misunderstandings}

Singer, I believe, misunderstands my position on a number of different counts. Two deserve a sketch here. The first, and the principal misunderstanding cannot, I think, fairly be laid at my door. For Singer interprets me as holding the view that utilitarianism ought to be abandoned because it fails to account for our obligation to be vegetarian! ( $p$. 326) But this extraordinary position is one I neither explicitly advance nor imply. What I do argue, though confessedly in only the barest outline, in my essay's second part, is that utilitarianism cannot adequarely account for our duties to severely mentally enfeebled human beings (henceforth referred to as "non-paradigmatic humans"2); that other, non-utilitarian theories (including my interpretations of Kantianism and egoism) aiso fail on this score; that a rights-based theory seems to provide the most adequate basis on which to rest our duties to nonparadigmatic humans; and, Einally, that consistency will oblige us to recognize the basic moral rights of many non-human animals, because of their relevant similarities to non-paradigmatic humans, if we are rationally constrained to recognize the basis moral rights of these humans. Tnus, it is because, in my view, utilitarianism, anong other failings, ${ }^{j}$ fails to provide an adequate basis on which to ground our duties to certain human beings, not because it fails to support vegetarianism, that I believe it ought to be abandoned. The obligation to be vegetarian, in other words, is, in my view, not a basis on which to test the adequacy of competing moral theories. It is, rather, a consequence that follows from our having developed that theory which, among the contenders, looks to be the most reasonable. Thus, to argue, as I do, that Singer fails to show that utilitarianism leads to the obligation to be vegetarian is a very different position than to aruge, as I most certainly do not, that "utilitarianism should be abandoned because it does not lead to vegetarianism." (p. 327)

A second misunderstanding concerns my view of the relevance of consequences within a rights-based theory. On this matter Singer writes the following:

Regan suggests that by basing the case for vegetarianism on animals' rights I 'could dispense with the need systematically to investigate the probably consequences of changing our eating habies'. This suggestion strikes me as quite wrong-headed, rather like telling the President that by basing his case on the moral principle that it is always legitimate to resist aggression, he can dispense with the need systematically to investigate the probable consequences of a nuclear reponse to Soviet military initiatives. In contrast to Regan, I think we should always try to find out as much as possible about the probably consequences of our actions ( $p .328$ ).

What I want to say is that I, too, think that consequences are relevant to the determination of what are our obligations, and that $I$, too, think it would be quite "wrong-headed" to exclude considerations about consequences altogether. This is a point I have gone to some length to try to make clear, not only in the particular case of vegetarianism ${ }^{4}$ but elsewhere, 5 and it is a point I shall return to in (3) below. The point I was trying to make in the passage alluded to by singer is not that consequences are always and totally irrelevant; rather, what I was suggesting is that if animals have rights, and if their rights are being violated by present farming methods, then one could argue that this treatment is wrong, whatever the 
consequences of these present practices are. For, if this treatment violates their rights, then, whatever the consequences are, one could maintain that this treatment is wrong. But though this is the central point I wished to make, in the passage alluded to by Singer, I do not believe 1 it is a point that is made clearly, and the fault, in this case of misunderstanding, ought certainly, I think, to be laid at my door.

\section{(2) The coherence of utilitarianism}

In my essay I distinguished between what I called the equality of interests principle and the equality of treatment principle. In his response, Singer writes as follows:

The only principle of equality I hold is the principle that the interests of every being affected by an action are to be taken into account and given the same weight as the like interests of any other being . . .

(U) tilitarianism presupposes this principle (the equality of interests principle). The principle of equality of intersts merely makes it explicit that, because the principle of utility is the sole basis of morality, no other principle will limit the application of the principle of utility, or affect the way in which it operates (pp. 328-29).

In my earlier critique of Singer I was prepared to grant the equality of interests principle (henceforth sometimes referred to as "tie equality principle") to utilitarianism, on the grounds that that theory presupposes it. I now have serious doubts about the wisdom of being so generous to utilitarianism, doubts which the passage from Singer, just quoted, intensify rather than placate. For if the equality principle is presupposed by the principle of utility, and if, in Singer's words, the equality principle "limit(s) the application of the principle of utility," then it appears inconsistent to claim that utility is "the sole basis of morality." For it cannot be true that utility is the sole basis if, in addition to utility, the equality principle also is basic to morality. And it cannot be true that utility forms the basis of morality after all,if, as Singer contends, the principle of utility "presupposes" that of equality and is "limtted" by the principle. It is, it seems to me, a deficient because incoherent ethical theory that asserts both that the principle of utility is the sole basis of moraltty and that there is another principle (equality) that is presupposed by utility and limits it.

But perhaps Singer believes that the equality principle is a formal, not a moral, principle, so that the limits it places on utilitarianism are not moral but logical or quasi-logical. And it is true that, if this is the way he views the equality principle, then the charge of incoherence, advanced in the argument in the preceding paragraph, could in principle be met. But only at a price. For, first, we will want a very careful argument before it can be reasonable to agree that equalicy is a formal principle, an argument which, I believe it is fair to say, Singer has not yet advanced in the writings presently available to us. 6 But, second, and for present purposes more importantly, if equality is supposed by Singer to have the status of a formal principle, then of course it cannot also be supposed that that principle is the exclusive property of utilitarlans. True, many non-utilitarians (e.g., Kant and Aquinas) have argued in ways that at least seem to violate the equality principle's strictures, arguing, it may be alleged, that though animals and humans have similar interests, the interests of humans nevertheless are more important than the like interests of animals. But from the fact, assuming that it is a fact, that some non-utilitarians have argued in this way, it does not follow that all non-utilitarians must do so. And this does not follow even if we suppose that all utilitarians have been uniformly successful in respecting the equality principle. 7 In particular, it does not follow that a rights-based theory, one in wilch basic moral rights are postulated even in the case of some non-human animals, must violate the principle of the equality of interests or cannot insist that this principle be honored. Thus, if, in order to avoid the problem of the coherence of his version of utilitarlanism, Singer were to endorse the view that the equality principle is a formal principle, then he would also be obliged to recognize that it is a principle whose use is not limited to utilitarian moralises.

The same is true of other consideracions singer advances in the course of orfering his utilitarlan basis for the obligation to be vegetarian. Many of these, too, are not in principle 
restricted to utilftarian moralists but mighe consistently be advanced by other, decidedly non-utilftarian theorists including those who advance a rightsbased theory. These considerations include the following:

(1) Modern farming methods inflict much suffering on animals.

(2) A vegetarian diet "does not involve great sacrifices, not in our health, nor in our capacity to feed the growing population, nor in the pleasures of the palate" (p. 333).

(3) Being a vegetarian is "something which 'underpins, makes consistent, and gives meaning to all our other activities on behalf of animals." (P. 336, quoted from Aninal Liberation, p. 171.)

(4) "(B)ecoming a vegetarian is a way of attesting to the depth and sincerity of one's belief in the wrongness of what we are doing to animals" (p. 337).

All these considerations are in principle available to advocates of positions other than the utilitarian one advocated by Singer, and though I do not think Singer actually says anything that clearly implies that he thinks otherwise, it is important to make this point very clear, since someone wight be misled into thinking that, since these considerations are of great moral importance and since they occupy a place of central importance in Singer's account of the utilitarian basis for vegetarianism, they are recessarily restricted to utilitarians. My point is that this would be as mistaken a view of the logic of these considerations as it would be to view the equality principle, if that principle is supposed to be formal, as the exclusive property of utilitarlans.

\section{(3) Singer's attempt to base vegetarianism on utility}

But the above considerations, though they are not limited to utilitarian moralists, cannot be denied them, either, and we may assume, for present purposes, that these considerations collectively do go some way toward providing the utilitarian basis for vegetarianisw that Singer seeks. The question is whether, when coupled with the other considerations Singer advances, the basis he seeks has been achieved. I do not believe it has, for several reasons. I shali limit myself to only two.
First, Singer, responding to various critics' accusations that being a vegetarian must be a largely symbolic gesture for someone with his utilitarian predilections, since one person's boycotting meat will fail to make any difference to the way animals are treated in factory farming, replies that in the case of chickens, for example, "there must be some point at which the number of vegetarians makes a difference to the size of the poultry industry. There must be a series of thresholds, hidden by the market system of distribution, which determine how many factory farms will be in existence. In this case one more person becoming a vegetarian will make no difference at all, unless that individual, added to the others who are already vegetarians, reduces demand below the tinreshold level at which a new factory farm would have started up (or an existing one would have remained in produetion, if industry is declining)" (p. 335). Whether we now know what these "thresholds" are is a matter I shall return to briefly, when I turn to my second point below. What I now wish to stress is the paradoxical nature of this aspect of Singer's utilitarian basis of the obligation to be vegetarian. What it comes to, I believe, is that, in being a vegetarian I am doing what I ought to do only if it happens to be true that enough other people happen also to be vegetarians so that, when the effects of their boycotting meat are joined with the effects of my boycott, it happens to be the case that some number of chickens that would have been raised in a factory farm are spared that fate. If, on the other hand, the effects of our collective boycott happen not to make any difference in the number of chickens raised intensively, then, in being vegetarians, we are not doing what we ought to do, not because of any failing on our part (assume we work very hard to persuade others but fail to do so), but because of the effects of the decisions of others (i.e., nonvegetarians), whose demand for meat more than offsets the effect of our boycott. But to make the rightness of what vegetarians do contingent upon the decisions of those very persons who are dotng what vegetarians deplore-and Singer's view does imply this, I think-is paradoxical at best, all the more so when we pause to observe that, on this view, all that non-vegetarians need do, in order to insure that they escape the obligation to be vegetarian, as this is determined by the vegetarian's impact on 
Iactory farding, is to continue doing precisely what it is that they are presently doing--namely living as non-vegetarians! And if, perchance, the ranks of vegetarians were to swell to such a degree that their collective impact on factory farming could close this or that intensive rearing operation, the nonvegetarians, given Singer's position, could still take steps to escape the obligatoriness of vegetarianism, as this is assessed by the impact of vegetarians on factory farming. All that non-vegetarians would need do is eat more meat, thereby negating the collective effect of the vegetarians. I am not saying that the non-vegetarians would be doing what is right in this case. Quite the contrary. What I an suggesting is that Singer cannot argue that what they are doing is wrong, by appeal to the impact of alternative diets on factory farning. Granted, the number of persons who are vegetarians does bear on the number of animals raised in factory farms; and granted that vegetarians must profoundly wish that their individual and collective efforts will ultimately reduce the number of animals so raised; nevertheless, the obligation to be vegetarian cannot be grounded in these considerations, I believe, except at the price of the paradox Singer's view is heir to.

My second point is this. The central problem for Singer, I believe, is that, in order for him consistently to press the moral case for vegetarianism, he must be in a position to claim to know both what are the likely consequences of a gradual or sudden sinift to a vegetarian diet, as compared with the consequences of the present global dietary habits, and to know that the consequences of the shift to vegetarianism are likely to be better, all considered, than the consequences that. would obtain from perpetuating present practices. In my previous essay I acknowledged the great debt we owe to Singer and others for awakening us to the harsh realities of factory farming. What I failed to take note of, and what Singer, in his reply, reafirms, is that he has also set forth other, relevant considerations that bear on the question of consequences--e. 8 ., that "a vegetarian diet does not involve great sacrifices, not in our health, nor in our capacity to feed the forwing world population, nor in the pleasures of the palate" ( $p .333$ ). Even granting these additional considerations, however, I believe that the epistenological problems that must haunt all versions of utilitarianist cast their oppressive shadow over Singer's actempt to base vegetarianism on his version of that theory. For it is not enough to know, for example, that there are "thresholds" beyond which the collective impact of vegetarians does make a difference to how many factory farms there are. One wants to know what these thresholds actually are. Or, again, it is not enough to know that, by a gradual or sudden switch, by a substantial number of present meat-eaters, "our capacity to feed the growing world population" will be increased. What one also wants to know is whether, given that we could feed more people, we (a) will and (b) ought to. As for (a), there are enormously complicated economic questions involved, in particular whether, given a substantial decline in the animal industry's demand for corn, oats, etc., there will be sufficiently attractive economic incentives for farmers to produce amounts of grain and other foodstuffs that would be sufficient to feed an ever growing world population, an economic possibility that needs a sound empirical basis, not hopeful speculation, if the case for its likelihood is to be established, as it must be if, like singer, we rest the case for vegetarianism on the likely consequences of alternative courses of action. And as for (b), what needs to be shown, not assumed, is that the consequences of feeding an ever expanding global population are preferable to taking other, possibly drastic steps (e.g., involuntary sterilization) to put a lid on population growth. Of course there are some for whom easy recourse to such drastic steps will clash with their understandings of basic human rights or common moral intultions. But it is absolutely essential to realize that Singer will have none of this--not appeals to moral rights, since such appeals are, to him, merely "a concession to popular rhetoric," not appeals to "our common moral intuitions" since, in his view, this "inbuilt conservatism. . is liable to take relics of our cultural history as the touchstones of morality" (p. 326). For Singer, all and everything turns on consequences. And, because of this, the burden of flxing and weighing all the relevant consequences must be dutifully borne by him, which is why his putative utilitarian basis for vegetarianism must in principle be far more complicated, I belleve, than even his reply suggests he thinks. All of the likely consequences, both of prevailing and alternative dietary 
practices, for all the affected parties, in all the affected parts of the globe, in both the short and the long run, must be ixed and weighed, and the case for vegetarianism must be established on this basis alone. I hope it neither is nor seems unfair to say that, despite the advances Singer has made in sketching the broad outlines of a utilitarian case for vegetarianism, he has yet to marshall enough detailed empirical findings (e.g., detailed studies regarding its impact on population growth) to give a finished or compelling utilitarian basis for the way of life he advocates.

Now, there is, I believe, a way around this problem for those who wish to argue for the obligatoriness of vegetarianism, and one that does not oblige us to endorse the "wrong-headed" view that consequences are altogether irrelevant to the determination of what is right or wrong. This is the position set forth in my original essay on the moral basis of vegetarianism. 10 It involves arguing, to summarize that position crudely, that the butden of proof falls on those who harm the innocent to show why, in doing so, they do not violate the right of the innocent not to be harmed, and that, unless or until those who themselves harm the innocent, or actively support others who do so, succeed in showing that they are not guilty of violating the rights of the innocent, we are justified in viewing their conduce as violative of the rights in question. These abstract principles are chen applied to the case of our culture's use of animals as a food source, both within and outside the context of factory farming, the conclusion being that unless or until we are shown that raising and killing animals do not violate their rights, we are rationally entitled to believe and morally required to act as if they do. Thus, considerations about consequences are nor ruled out as irrelevant by my position, since whether rights are violated will turn on considerations that include considerations about consequences. But, unlike Singer's, tny position does not put the burden of proof on me to $f i x$ and weigh all the likely consequences, on all the interested parties, in all parts of the globe, etc. The burden is placed on the non-vegecarian.

The fact that wy position does not require that the moral basis of vegetarianism can be advanced only on the condition that I (or other vegetarians) succeed in fixing and weighing all the relevant consequences is, I think, one of its significant strengths, just as the opposite requirement, in the case of Singer's position, is, I think, one of its special weaknesses. Whether $1 t$ is possible to provide a rationally compelling theoretical basis for a position like mine without having recourse to rights is unclear to me. But unless the burden of proof is shifted, as my argument attempts, the case for vegetarianism can never in principle be any more certain than our knowledge concerning the likely consequences, of our being or not being vegetarians, on all those affected, in all parts of the globe, etc., etc. The enormous burden of providing this elusive knowledge, I believe, should be borne, not by those who are vegetarians, but by those who are not, and it is one of the virtues of the use of the notion of moral rights, a virtue that utilitarianism lacks, that it provides us with the argumentacive means of shifting the burden to those who ought to bear it.

\section{Tom Regan \\ North Carolina State University}

\footnotetext{
Uuless otherwise indicated, page references following quotations are to this essay by Singer.

2 I have explored the moral status of non-paradigmatic humans in some detail. See my "An Examination and Defense of One Argument Concerning Animal Rights," Inquiry, Summer, 1979.

${ }^{3}$ The difficulties justice causes for utilitarianism are well known, but I an inclined to believe that considerations as diverse as the theoretical foundations of environmental ethics and the value of friendship also highlight utilitarlanism's shortcomings. On the ill-fit between utilitarianism and environmental ethics. see my "The Nature and Possibility of An Environmental Ethic" (Environmental Ethics) forthcoming. On the difficulties the value of friendship causes for utilitarian theory, see Iny "A Refutation of Utilitarianism" (under review).

4 See in particular my "The Moral Basis of Vegetariantsw," The Canadian Journal of Philosophy, October, 1975. Selections from this essay are reprinted in Animal Rights and Human Obligations, edited by Tom Regan and Peter Singer (Englewood Cl1ffs: Prentice-Ha11) 1976 and in
} 
Today's Moral Problems, Second Edition, edited by Richard Wasserstrom (New York: Macmillan) 1979. See also my "Arimal

Rights, Human Wrongs," Environmental Ethics, Summer, 1980. This essay also will appear, in Polish, in Eryka, forthcoming.

5ee, for example, my "A Defiense of Pacifism," The Canadian Journal of Philosophy, January, 1972, reprinted in Today's Moral Problems, First Edition, edited by Richard Wasserstrom (New York: Macmillan) 1975.

Gperhaps it will be objected that singer does not regard the equality principle as a principle that is distinct from the principle of utility, despite the fact that he states that utflitarianism "presupposes" the equality principle. If this were true, then the sting would be taken out of the charge of incoherence just leveled against his position. The available evidence seems to be against this defense of Singer, however, since we find, in his Practical Ethics, that Singer attempts to argue to the principle of utility from acceptance of the equality principle (Practical Ethics, Cambridge University Press, 1980, pp. 1112). All indications are, then, that Singer does regard the two principles as distinct and also believes that equality is more basic than utility. And that, as I have argued in the above, is 1ncoherent, if (a) the principle of utility is said to be "the sole basis of morality," if (b) the equality principle is itself viewed as a substantive moral principle, and if (c) the latter principle is "presupposed" by the former, in the sense that we are supposed to be able to argue from acceptance of the equality principle to acceptance of that of utility.

${ }^{7}$ Singer at least suggests that utilitarians historically have been successful in respecting the equality of interests principle, and it is true that both Bentham and Mill, for example, clearly indicate that animal interests count for something. But it is not clear at all that they think that we are constrained to count the like interests of animals and humans equaliy. On this see my discussion of Mill in "The Moral Basis of Vegetarianism," op. cit.

The pioneering work of Ruth Harrison always deserves special mention. See her Animal Machines (London: Vincent Stuart) 1964.

9peter singer, "The Parable of the Fox and the Unliberated Animals," Ethics, January, 1978, p. 122.

IOSee, again, my "The Moral Basis of Vegetarianism," ㅇ․ cit. 